REVISTA DE DERECHO UNED, NÚM. 24, 2019

\title{
LA AUTODETERMINACIÓN DE GÉNERO EN LA INTERSEXUALIDAD A PROPÓSITO DE D.1,5,10 PAUL. 1 AD SAB.
}

\author{
SELF-DETERMINATION OF GENDER IN INTERSEXUALITY \\ FOR THE PURPOSE OF D.1,5,10 Paul. 1 ad Sab.
}

\begin{abstract}
MARÍA JosÉ TORREs PARRA
Profesora de Derecho Romano. Universidad Complutense de Madrid
\end{abstract}

Resumen: Con este artículo pretendemos analizar la importancia que tiene la determinación del sexo. Esta exigencia, consecuencia de las limitaciones en la capacidad jurídica y de obrar de las mujeres, tiene especial trascendencia, como demuestran los textos, en materia sucesoria. El paso previo es averiguar qué criterio resulta más idóneo para asignar un sexo a las personas con ambigüedad genital externa. Las alternativas, reducidas exclusivamente al binomio hombre/mujer, son: la coincidencia con la normal apariencia masculina o femenina o la autopercepción que el hermafrodita tiene de sí mismo.

Aunque no expresamente tratados en las fuentes, en derecho romano el hermafroditismo plantea otras controversias unas, relacionadas con la exigencia de forma humana como requisito de la personalidad jurídica, y otras acerca de su consideración como enfermedad o defecto físico.

Palabras claves: Hermafroditismo. Intersexualidad. Forma humana. Enfermedad. Autodeterminación de género.

Abstract: With this article we intend to analyze the importance of determining sex. This demand, as a consequence of the limitations on 
women's legal capacity and capacity to act, is of special importance, as demonstrated by the texts on succession matters. The previous step is to find out which criterion is most suitable to assign a sex to people with external genital ambiguity. The alternatives, reduced exclusively to the binomial man/woman, are: the coincidence with the normal masculine or feminine appearance or the self-perception that the hermaphrodite has of his-herself.

Although not expressly treated in the sources, in Roman law the hermaphroditism raises other controversies, related to the requirement of human form as a requirement of legal personality, and others about its consideration as a disease or physical defect.

Keywords: Hermaphroditism. Intersexuality Human form. Selfdetermination of gender.

Recepción original: 23/10/2018

Aceptación original: 04/02/2019

Sumario: I. Introducción. II. Terminología. III. Los hermafroditas en las fuentes. III.A. Fuentes extrajurídicas. III.B. Fuentes jurídicas. IV. Los hermafroditas y la forma humana. V. La determinación del sexo de los hermafroditas. VI. La participación de los hermafroditas en la vida jurídica. VII. Algunas conclusiones.

\section{INTRODUCCIÓN}

El primer criterio para categorizar a las personas recién nacidas es atribuirles un sexo que concuerde con la apariencia física de sus genitales externos. Con las excepciones que algunos países han incorporado en sus legislaciones, la determinación del sexo se plantea en los normalizados términos binarios hombre/mujer propios del modelo anatómico-biológico que hace coincidir los atributos físicos del sujeto con la apariencia esperada de hombres o mujeres.

Pero además de asignarles un sexo biológico, las personas precisan de un sexo jurídico. Esta necesidad responde en los ordenamientos jurídicos modernos - como el español- a la obligatoria inscripción registral del sexo del neonato. Puestos a determinar el sexo biológico y, en su caso, legal, las dificultades para categorizar conforme a los estándares de hombre/mujer aparecen cuando la apariencia externa no coincide con la que se entiende correspondería a mujeres y hombres. Si excluimos otros criterios que no sean los de la apariencia física, la normalidad deviene anormalidad cuando la 
persona tiene a la vez genitales masculinos y femeninos. Este es el fenómeno del hermafroditismo.

Tratándose de un estudio jurídico circunscrito al derecho romano, debemos prescindir de los debates -interesantísimos, sin duda- que este tema suscita en otros foros y disciplinas (medicina, antropología, ética, por citar algunos) y, aún desde el punto de vista jurídico, en los derechos positivos.

\section{TERMINOLOGÍA}

La limitación del objeto de este trabajo a una determinada época de la historia jurídica exige hacer una precisión terminológica: ¿nos debemos referir a estas personas llamándolas hermafroditas o intersexuales?

En el habla común de la calle y en el lenguaje médico es habitual el empleo de los términos hermafrodita e intersexual como sinónimos para referirse a las personas con ambigüedad genital externa. Sin embargo, hermafrodita, intersexual o andrógino - vocablo éste que también se emplea para referirse al estado de quien reúne en su constitución corporal caracteres masculinos y femeninos-, ni etimológicamente significan lo mismo ni describen la misma realidad.

La etimología del nombre «Hermafroditos» es discutida. Hermaphroditus era un personaje mitológico hijo de Hermes y Afrodita o Venus que participaba de los dos sexos ${ }^{1}$. El término intersexual se refiere a las personas que se encuentran entre dos sexos, mientras que el sustantivo intersex describe una amplia gama de variaciones naturales del cuerpo.

En sus orígenes, hablar de hermafroditismo era adentrarse en un mundo sobrenatural y acientífico, de ahí que el estudio científico de este fenómeno exigiera un cambio de nomenclatura. Se entendía que hablar de hermafroditas o intersexuales no era apropiado porque, además de faltarle rigor científico, los términos tenían connotaciones ignominiosas y estigmatizantes que convenía desechar. Hoy, el empeño está en buscar la mejor denominación para esta realidad. El término médico más usado es el de estados intersexuales, mientras que en el mundo jurídico es más habitual hablar de personas intersexuales.

${ }^{1}$ Lat. Hermaphroditus, gr. Hermaphróditos. El término deriva de «Hermético» y está compuesto de Hermês, nombre griego del dios Mercurio. COROMINAS, J. - PASCUAL, J.A., Diccionario crítico etimológico castellano e hispánico, III, ed. Gredos, Madrid, 1980, pág. 348. 
Para ser fieles a la denominación que aparece en el Digesto, en este trabajo solo emplearemos el término hermafrodita donde, conviene recordarlo, la palabra no tiene matiz peyorativo ${ }^{2}$.

\section{LOS HERMAFRODITAS EN LAS FUENTES}

El hermafroditismo, como hecho natural de la reproducción entre seres vivos, es conocido desde la Antigüedad y desde entonces ha provocado desconcierto cuando no, temor. El mito de seres andróginos se remonta al comienzo de los tiempos.

El problema de la diferenciación sexual y, con ello, el del nacimiento de hermafroditas, preocupó ya a los filósofos antiguos: desde Demócrito hasta Galeno buscaron explicaciones para la determinación embrionaria del sexo. Aristóteles, por ejemplo, atribuye el nacimiento de humanos hermafroditas a una desviación que se produce en el desarrollo humano.

\section{III.A. Fuentes extrajurídicas}

Antes de que los juristas buscaran soluciones a los problemas planteados por los hermafroditas en el quehacer jurídico, historiadores y literatos de la Antigüedad ya los habían mencionado en sus escritos. Las referencias de las fuentes extrajurídicas al hermafroditismo y las circunstancias relacionadas con él relatan hechos más próximos a lo mitológico y sobrenatural que a la realidad. Esas mismas fuentes recuerdan cómo el nacimiento de seres hermafroditas presagiaba calamidades y desgracias en la trayectoria vital del neonato y en el de su familia.

Ovidio, en las Metamorfosis (IV,285-295) relata la historia de Hermaproditus. Este joven era hijo de Hermes y Afrodita y después de unirse a la ninfa de la fuente de Sálmacis se transformó en un ser de doble sexo con un estatus debilitado: «Nec duo sint, et forma du-

${ }^{2}$ La cuestión de la nomenclatura no es pacífica. Aún persisten las dudas sobre la conveniencia de descartar unos términos y utilizar otros más respetuosos con la dignidad humana. Eso sin despreciar el debate sobre las implicaciones políticas que tiene el uso del lenguaje jurídico, médico o social. Sobre el empleo de los términos en el discurso médico y sus repercusiones sociales, vid. por todos, GARCÍA DAUDER, S. - ROMERO BACHILLER, C., «Los desplazamientos políticos de las categorías médicas: actores, discursos y relaciones en la controversia "Alteraciones del desarrollo sexual"versus "Intersexualidad" », en PÉREZ SEDEÑo, E. - IBÁÑEZ MARTín, R., (eds.), Cuerpos y diferencias, ed. Plaza y Valdés, Madrid, 2012, págs. 213-240. 
plex, nec femina dici. Nec puer ut possint, neutrumque et utrumque videtur» Aulo Gelio citando a Plinio dice en Noct. Att. IX,4,16: «Idem Plinius in eodem libro uerba haec scripsit: Gignuntur homines utriusque sexus, quos "hermaphroditos" uocamus, olim "androgynos" uocatos et in prodigiis habitos, nunc uero in deliciis". Efectivamente en el capítulo que Plinio dedica a los prodigios encontramos las palabras reproducidas por Aulo Gelio: «Gignuntur et utriusque sexus quod hermaphroditos vocamus, olim androgynos vocatos et in prodigiis habitos, nunc vero in deliciis (Historia Natural, VII,3,34).

El alumbramiento de estos seres apartados de la normalidad era una señal divina de mal augurio que anunciaba la llegada de desgracias y que perturbaban la paz, de ahí la necesidad de acabar con la vida de estos seres para aplacar la ira de los dioses. Séneca (De ira 1,15,2: «...portentosos fetus exstinguimus, liberos quoque, si debiles monstrosique editi sunt, merginus, nec ira, sed ratio est a sanis inutilia secernere».) y Cicerón admiten que los nacidos como monstruos sean eliminados: "Deinde, quom esset cito necatus tamquam ex XII tabulis insignis ad deformitatem ouer, breui tempore nescio quo pacto recreatus multoque taetrior et foedior renatus est.» (de leg. 3,8,19).

\section{III.B. Fuentes jurídicas}

La mención expresa de los hermafroditas en dos fragmentos de la compilación justinianea contradice la afirmación de wINDSCHEID de que el derecho romano no reconoció el hermafroditismo ${ }^{3}$. El jurista alemán no ofrece argumentos para justificar su afirmación, pero podría pensarse que es la consecuencia de tener que elegir entre hombre o mujer como únicas alternativas posibles para determinar el sexo de las personas. Ulpiano 1 ad Sab.-D.1,5,10, refiriéndose al sexo que corresponde a los hermafroditas, implícitamente excluye que una persona pueda ser hombre y mujer al mismo tiempo al reducir los términos de la elección a las categorías hombre o mujer.

$\mathrm{Si}$, como recuerda BONFANTE ${ }^{4}$, los hermafroditas no constituyen una clase especial de sujetos, es claro que con los criterios clasificatorios manejados por el derecho romano no cabe más sexo legal que el de hombre o mujer. Con ello otras categorías sociales o jurídico-

3 wINDSCHEID, B., Lebruch des Pandektenrechts, Diritto delle Pandette, (trad. italiana a cura di FADDA e BENSA), I, Turín, 1925, pág. 157 y n.2.

${ }^{4}$ BONFANTE, P., Instituciones de Derecho Romano ${ }^{3}$, (trad. BACCI , L. y LARRosa A.), ed. Reus, Madrid, 1965, pág. 58.

() UNED. Revista de Derecho UNED, núm. 24, 2019 
legales (por ejemplo, sexo indeterminado o tercer sexo) aptas para operar en el mundo jurídico resultarían irrelevantes ${ }^{5}$.

En el Digesto solo dos textos tratan expresamente de los hermafroditas: uno es el ya mencionado de Ulpiano D.1,5,10 que, como veremos, plantea el criterio general para determinar el sexo:

Quaritur hermaphroditum cui comparamus? Et magis puto eius sexus aestimandum qui eo prevalet,

y el otro, también de Ulpiano ( 3 ad Sab.), recogido por los compiladores en D.28,2,6,2 sobre la condición que debe cumplir el hermafrodita para intervenir en un negocio jurídico concreto:

Hermaphroditus plane, si in eo virilia praevalebunt, postumum heredem instituere poterit,

Antes de estudiar cómo abordan los juristas romanos la cuestión del hermafroditismo conviene recordar que la determinación del sexo de las personas hermafroditas está estrechamente ligada a la distinta capacidad jurídica y de obrar que el ordenamiento jurídico romano reconoce a mujeres y hombres. Pertenecer a uno u otro sexo es relevante porque condiciona a aquellas, por tanto, determina que los negocios en los que participan estos sujetos surtan efectos jurídicos. El sexo (anatómico) se convierte así en un prius de la validez de los negocios jurídicos que celebren.

Papiniano 31 quaest.-D.1,5,9 reconoce el diferente trato que reciben los hombres en perjuicio de las mujeres:

In multis iuris nostri articulis deterior est condicio feminarum quam masculorum.

Mucho se ha escrito sobre la distinta - y peor - consideración jurídica de la mujer en Roma. Sin ir más allá en los argumentos que explican el trato diferenciado de mujeres y hombres, resulta innegable que éste es un correlato de los roles y de la desigual consideración social reconocida a varones y hembras.

De los dos fragmentos que mencionan a los hermafroditas, el de Ulpiano (1 ad Sab.), D.1,5,10 colocado tras la declaración de Papiniano sobre la distinta condición de mujeres y hombres (D.1,5,9

\footnotetext{
5 Señala thomas, y., «La división de los sexos en Derecho romano», en DUBY, G. - PERROT, M. (dir.), Historia de las mujeres en Occidente, T.1 (trad. M.A GALMARINI), ed. Altea, Taurus, Alfaguara S.A., Madrid, 1991, págs. 116-117, que el hermafroditismo, al menos desde la perspectiva jurídica, no se considera un tertius genus. Cosa distinta es que, en la tradición médica antigua, al no existir obligación de identificar los sexos conforme a categorías rígidas y predeterminadas fuera posible hablar de uterque sexus entendido como mezcla de sexos.
} 
Pap. 31 quaest.), plantea el principal problema (jurídico) de los hermafroditas, esto es, la necesidad de encontrar un criterio para determinar el sexo cuando de la apariencia física (externa) no resulte indubitada la pertenencia al sexo masculino o femenino.

El nacimiento de un hermafrodita es una anomalía que desafía el aspecto físico habitual esperado de hombres y mujeres. La no adecuación al canon de la apariencia humana justificaría las dudas acerca de si el neonato nacido con ambigüedad genital externa cumple los requisitos para ser considerado persona. A pesar de la extrañeza que provocan estos partos, los fragmentos que abordan el requisito de la figura humana no mencionan expresamente a los hermafroditas. Por el contrario, en los pasajes que tratan de ellos la discusión se centra en que el reconocimiento de capacidad para intervenir en ciertos negocios jurídicos depende de que sean hombres o mujeres. Aunque se trata de dos cuestiones de naturaleza distinta, en el caso de los hermafroditas ambos aspectos (forma humana y pertenencia a sexo masculino o femenino) están estrechamente relacionados.

Es cierto que en la enumeración de las condiciones para reconocer la existencia de las personas físicas las fuentes ofrecen testimonios contradictorios, y aunque no encontramos una exposición general sobre los mismos ${ }^{6}$, el total desprendimiento del claustro materno $^{7}$, el nacimiento con vida ${ }^{8}$ y la forma humana ${ }^{9}$ son las tres condiciones mínimas para hablar de persona.

${ }^{6} \mathrm{Vid}$. ALBANESE, B., Le persone nel diritto privato romano, ed. Universidad de Palermo, Palermo, 1979, págs. 13 y ss.; PANERo, R., Derecho Romano, ed. Tirant lo Blanch, Valencia, 1997, pág. 211 n.27.

${ }^{7}$ D. $25,4,1,1$ Ulp. 24 ad ed.: (...) partus edatur mulieris portio est vel viscerum y D.35,2,9,1 Pap. 19 quaest.: (...) partus nondum editus homo non recte fuisse dicitur.

${ }^{8}$ D. 50,16,129 Paul. 1 ad leg. Iul. et Pap.: Qui mortui nascuntur, neque nati neque procreati videntur, quia numquam liberi appellari potuerunt. Al nacimiento con vida, algunos autores añaden la exigencia de un plazo mínimo de gestación. Sobre el reconocimiento de personalidad al nacido prematuramente y su posible condición de abortus, vid. AMBROSINO, R., "Il requisito della vitalità per l'acquisto della capacità giuridica in diritto romnano", RISG (1940), págs. 1 y ss.

${ }^{9}$ Mulier si monstruum Paul, Sent. 4,9,3 = D.1.5.14 pr.: Non sunt liberi, qui contra formam humani generis converso more procreantur: veluti si mulier monstrosum aliquid aut prodigiosum enixa sit (...) y Scolio 2, Bas. 46,1,11; y una constitución del año 530 recogida en CJ.6,29,3,1: Veteres animi turbati sunt, quid de paterno elogio statuendum sit. cumque sabiniani existimabant, si vivus natus est, etsi vocem non emisit, ruptum testamentum, apparet, quod, etsi mutus fuerat, hoc ipsum faciebat, eorum etiam nos laudamus sententiam et sancimus, si vivus perfecte natus est, licet ilico postquam in terram cecidit vel in manibus obstetricis decessit, nihilo minus testamentum corrumpi, hoc tantummodo requirendo, si vivus ad orbem totus processit ad nullum declinans monstrum vel prodigium. 
De estos tres, el último (forma humana) es el más cuestionado y el que presenta mayores dudas y dificultades. Por un lado, no hay acuerdo en si su exigencia aparece en derecho clásico o en derecho postclásico y justinianeo ${ }^{10}$; por otro, si la aplicación de la lex Iulia et Papia Poppaea y el Senadoconsulto Tertuliano influyeron en la interpretación de lo que debía entenderse por forma humana.

Volvamos al requisito de la forma humana. La necesidad de que el producto del parto pertenezca a la especie humana excluye de la categoría de sujetos de derecho, en palabras de GUARINO ${ }^{11}$, a los animales subhumanos y a los seres sobrehumanos. La consideración de estos seres fantásticos prueba lo inapropiado de exigir que las personas tengan figura humana ya que la reproducción entre humanos solo es posible cuando los progenitores pertenecen a la misma especie. El nacimiento de un ser humano producto del apareamiento con un individuo de otra especie es biológicamente imposible.

No obstante, aunque el nacimiento de seres extraordinarios que desafían el orden natural de las cosas debe considerarse un producto de la fantasía en un tiempo en el que no existía una nítida diferencia entre las cuestiones religiosas y las cuestiones civiles, no es menos cierto que estos nacimientos anómalos suscitaron dudas en la jurisprudencia romana. Los juristas romanos utilizaron términos diferentes para referirse a estos partos: portentosus, monstruosos, ostetum, debilis y prodigiosus.

Ulpiano nos recuerda la definición de ostentum dada por Labeón: «ostentum» Labeo definit omne contra naturam cuiusque rei genitum factumque. duo genera autem sunt ostentorum (D. 50,16,38 Ulp. 25 ad ed.),

para después referir las categorías que existen de ostentum:

unum, quotiens quid contra naturam nascitur, (...) cum quid prodigiosum videtur,

y como ejemplos, de la primera:

tribus manibus forte aut pedibus aut qua alia parte corporis, quae naturae contraria est (...),

${ }^{10}$ No todos los autores coinciden en que la exigencia de la forma humana estuviera vigente en el derecho clásico. Con distintos argumentos estos autores la retrasan hasta el derecho postclásico y justinianeo. Sobre la cuestión, vid. ASTOLFI, R., Lex Iulia et Papia, CEDAM, Padua 1970, págs. 175 n.25; IMPALLOMENI, G., «In tema de vitalitá e forme umana como requisiti essenziali alla personalità», IURA 22 (1971), págs. 99-120 (en concr. pág. 117).

11 GUARINO, A., Diritto privato romano ${ }^{8}$, ed. Jovene, Nápoles, 1988, págs. 263 y ss. 
y de la segunda:

alterum (...) quae graeci fantasmata vocant.

El texto ejemplifica la confusión de conceptos y, por ende, la ausencia de un criterio para diferenciar monstrum de prodigiosus.

Con la misma idea de nacidos sin forma humana por ser contra natura genitum utiliza Paulo 4 Sent. el término monstrum en D. $1,5,14$ :

Non sunt liberi, qui contra formam humani generis converso more procreantur: veluti si mulier monstrosum aliquid aut prodigiosum enixa sit $(\ldots)^{12}$.

A continuación, Paulo menciona a los nacidos con más miembros de lo habitual:

Partus autem, qui membrorum humanorum officia ampliavit, aliquatenus videtur effectus,

estos inter liberos connumerabitur pues parecen seres normales y perfectos.

El repaso de la literatura especializada muestra las controversias sobre el significado exacto de estos términos ${ }^{13}$. La procedencia de todos es distinta, pero todos tienen en común, al menos en los primeros tiempos del derecho romano, el ser propios del lenguaje religioso ${ }^{14}$. El monstrum equivaldría a un ser prodigioso de carácter sobrenatural. Para referirse al presagio se emplearían los términos

12 Paul. Sent. 4,9,3: Mulier si monstrosum aliquid aut prodigiosum enixa sit, nihil proficit: non sunt enim liberi, qui contra forman humani generis converso more procreantur. 4. Partum, qui membrorum humanorum officia duplicavit, quia hoc ratione aliquatenus videtur affectum, matri prodesse placuit.

13 Dudas sobre su significado que también aparecen en las fuentes extrajurídicas, así Festo, 284,4: Portenta existimarunt quidam gravia esse, ostenta bona: alii portenta quedeam bona, ostenta quaedam tristia appelllari. Portenta, quae quid porro tendatur, indicent: ostenta, quae tantum modo ostendant; monstra <quae> praecipiant quoque remedia. Varrón Gram. lat: «ostentum, quod aliquid hominibus ostendir; prtentum quod porro dirigir: miraculum quod mirum est; monstruo, quod monet.

Un repaso a las opiniones sobre el origen y significados de los términos en LANFRANCHI, F., NNDI «ostetum», T.12, Turín 1965, págs 262-263.

${ }^{14}$ En el lenguaje religioso el término monstrum se refiere a la voluntad de los dioses. Para hablar de presagio se emplean los términos ostetum y portetum que pertenecen a la lengua augural. Sobre la cuestión, ALEMÁN, A., "La forma humana y su vinculación con la viabilidad: precedente romano del artículo 30 del Código Civil ", en Actualidad Civil n. . 35, octubre 1999, págs. 1059-1071. ID., "Precisiones terminológicas sobre ostentum D.50,16,38 (Ulpianus Libro 25 ad edictum)», en Fundamenta Iuris, ed. Universidad de Almería, Almería, 2012, págs. 49-64.

(c) UNED. Revista de Derecho UNED, núm. 24, 2019 
ostetum y portentum: el último para designar los fenómenos contrarios a la naturaleza y el primero para resaltar los defectos físicos o anomalías incompatibles con la forma humana.

Más allá de los matices semánticos de estos términos o de la sinonimia entre ostetum, portentum, monstrum o prodigium, lo que sí parece relevante es que la exigencia de la forma humana para el reconocimiento de personalidad está relacionada con el requisito de la viabilidad (término polisémico y tampoco exento de polémica); en concreto de la viabilidad impropia de la que habla IGLESIAS ${ }^{15}$.

Se trate de partos contra natura o de partos compatibles con la forma humana generis, lo trascendente es averiguar qué consecuencias tienen estos nacimientos. Sobre este punto el distinto parecer de los juristas, producto de la escasa precisión terminológica, ha suscitado interpretaciones diversas entre los autores.

Los siguientes textos se refieren a las consecuencias:

En primer lugar, D. 50,16,135 (Ulp. 4 ad Iul. et Pap.):

Quaeret aliquis, si portentosum vel monstrosum vel debilem mulier ediderit vel qualem ${ }^{16}$ visu vel vagitu novum, non humanae figurae, sed alterius, magis animalis quam hominis, partum, an, quia enixa est, prodesse ei debeat? ${ }^{17}$ et magis est, ut haec quoque parentibus prosint: nec enim est quod eis imputetur, quae qualiter potuerunt, statutis obtemperaverunt, neque id quod fataliter accessit, matri damnum iniungere debet ${ }^{18}$.

El texto ulpianeo trata de una cuestión general a propósito de la aplicación de la lex Iulia et Papia: si el nacimiento sin forma humana o con defectos aprovecha o no a la madre. Ulpiano da una respuesta afirmativa, y aunque no se pronuncia sobre si el neonato monstrum o prodigium es o no persona, puede deducirse que la consideración

${ }^{15}$ La viabilidad impropia identificada con la ineptitud orgánica del partus madurus para continuar viviendo se contrapone a la viabilidad en sentido propio en la que el feto no ha alcanzado el grado suficiente de madurez para seguir viviendo fuera del claustro materno. IGLESIAS, J., Derecho Romano. Historia e Instituciones ${ }^{11}$, ed. Ariel, Barcelona, 1994, pág. 109.

${ }_{16}$ qualem Ins. Sennetomius.

17 Seqq. Inst. (Kuebler).

18 [et magis- fin] interpolado. Vid. Index Interp. ad legem. En general, las razones para considerar interpolado todo el fragmento son, a juicio de DALLA, D., "Status e rilevanza dell'ostentum», en Sodalitas, Scritti in onore di A. Guarino, vol. 2, Nápoles, 1984, págs. 519-532 (en cr.525 n.13), la estructura formal del texto, la no coincidencia entre singular y plural y la mención indiferenciada de matri y parentes. En el mismo sentido Burdese, A., Manuale di Diritto Romano, Padua. 1964. 
como personas solo se admite para que la madre se beneficie del ius liberorum ${ }^{19}$.

El mismo Ulpiano considera que quien nace vivo, pero no perfecto, invalida el testamento:

D. 28,2,12,1 (Ulp. 9 ad Sab.): Quid tamen, si non integrum animal editum sit, cum spiritu tamen, an adhuc testamentum rumpat? et $^{20}$ tamen rumpit.

Por tanto, se les aplicaría el mismo régimen que a los hijos vivos y perfectos. Hay que suponer que el así nacido entraría en la primera categoría mencionada por Ulpiano en D.50,16,38.

\section{D.1,5,14 Paul. (4 Sent.):}

Non sunt liberi, qui contra formam humani generis converso more procreantur: veluti si mulier monstrosum aliquid aut prodigiosum enixa sit. partus autem, qui membrorum humanorum officia ampliavit, aliquatenus videtur effectus et ideo inter liberos connumerabitur.

Por último, también de Paulo, Sent. 4,9,3-4:

Mulier si monstruosum aliquid aut prodigiosum enixa sit, nihil proficit: non sunt enim liberi, qui contra formam humani generis converso more procreantur. Partum, qui membrorum humanorum officia duplicavit, quia hoc ratione aliquatenus videtur effectum, matri prodesse placuit.

Paulo (ST 4,9,3-4= D.1,5,14) contabiliza entre los hijos a quienes solo tengan defectos físicos, no así los neonatos contra figura humanis.

Para explicar la discrepancia entre Ulpiano y Paulo se ha argumentado que la postura más flexible de Ulpiano es una consecuencia del objetivo que Augusto pretendió al aprobar la lex Iulia, esto es, premiar a quienes tuvieran descendencia. En cambio, la solución de Paulo se entiende a la luz del senadocosulto Tertuliano que permitió a la madre con ius liberorum suceder en los bienes del hijo ${ }^{21}$.

19 Excedería de nuestro propósito el estudio de las dudas que suscita este fragmento y los citados de Paulo D.1,5,14 y PS 4,9,3-4. Remitimos en este punto a las consideraciones, críticas y contra críticas de IMPALLOMENI, G., "In tema di vitalità», cit., págs. 99-120. DALlA, D., "Status», cit.; ID., L'íncapacitá sessuale in diritto romano, Giuffré, Milán 1978, págs. 145 y ss.

${ }^{20}$ Hoc: hoc. ins. $F^{2}$.

21 A juicio de BIONDI, B., Istituzioni di diritto romano ${ }^{5}$, ed. Giuffrè, 1972, el monstrum le sirve a la madre para alcanzar el ius liberorum en el marco de la lex Iulia; en cambio el monstrun no computaría a efectos del SC Tertuliano. En el mismo sentido Iglesias, J., Derecho Romano, cit., págs. 109-110. 


\section{LOS HERMAFRODITAS Y LA FORMA HUMANA}

En los fragmentos analizados es indiscutible cómo en el ideario de la vida social y, por ende, en el contenido del derecho persiste la contaminación de lo fantástico y de lo religioso en la cosmovisión de la realidad. La indiferenciación entre lo real y lo imaginario repercute en la consideración social y en la regulación jurídica de las cuestiones relacionadas con los hermafroditas. ¿Tienen estos forma humana? ¿En qué categoría de las manejadas por los juristas romanos se debería incluir a los hermafroditas? Su particular constitución física ¿es una anomalía?, ¿un defecto físico?, ¿una deformidad?...

Veamos cómo abordan los textos estas cuestiones. El nacimiento de los hermafroditas, como hemos visto, rompe la armonía natural de las cosas. Esta ruptura de la pax deorum provoca la necesidad inmediata de restaurar el orden natural, por eso su eliminación no se entendía un acto delictivo, sino un acto necesario de expiación con el que aplacar la ira de los dioses ${ }^{22}$.

Una interpretación rigurosa de la forma humana excluiría a los hermafroditas de la categoría de personas. Sin mencionar expresamente a los neonatos hermafroditas, las XII Tablas permiten al padre matar a la criatura que naciera con alguna deformidad sin que de ello se derivara responsabilidad para el progenitor ${ }^{23}$ :

... cito neonatus tanquam ex XII tabulis insignis ad deformitatem pueri» (Tab.4,1).

Esta disposición mencionada por Cicerón ${ }^{24}$ y de la que, como recuerda BONFANTE, ignoramos cómo se gestó, ${ }^{25}$ se explica porque en la época primitiva de Roma los partos contra natura (la expresión ad deformitatem del precepto decenviral hay que referirlo a estos alumbramientos), se interpretaban como un presagio de desgracias que era preciso cambiar mediante ceremonias expiatorias que concluían con la muerte del neonato.

${ }^{22}$ Cfr. Delcourt, M., Hermaphrodite. Mythes et rites de la bisexualité dans l'Antiqueté Classique, París, 1958.

${ }^{23}$ NARDI, E., L'otre dei parricidi e le bestie inclusse, Milán ,1970 pág. 47 n. 61.

${ }^{24}$ Dionisio de Halicarnaso II, 15 atribuye a Rómulo el permiso para matar a los niños monstruosamente deformes, mientras que Cicerón (de leg. 3,8,19) lo sitúa en las XII Tablas.

${ }^{25}$ Bonfante, P., Corso di diritto romano, vol. III, Diritto di familia, ed. Giuffrè, Milán, 1963, págs. 102-103, habla de la posible obligación del paterfamilias de matar al parto monstruoso. Esta práctica cumpliría una función análoga al despeñamiento por el monte Taigeto de los discapacitados y deformes que se practicaba en Esparta. 
No es erróneo afirmar que en la Antigüedad el porcentaje de neonatos con ambigüedad genital fue - como lo es hoy- escasísimo ${ }^{26}$, tampoco lo es que estos nacimientos debieron suscitar dudas sobre si cumplían o no el requisito de la forma humana. La cuestión es qué términos de los recogidos en las fuentes sería el más adecuado para referirse a los hermafroditas: ¿el ostentum definido por Labeón? ¿el monstrum mencionado por Paulo (4 Sent.) en D. 1,5,14?, ¿sería un portentum o un prodigius?

Como ya hemos mencionado, en las fuentes romanas que abordan la cuestión de la forma humana no se menciona expresamente a los hermafroditas. No se incluirían entre los partus qui membrorum humanorum officia ampliavit (Paul. 4 Sent., D.1,5,14), pero sí tendrían cabida en el ostetum del nacido contra natura del que habla Labeón (D. 50,16,38 Ulp. 25 ad ed.) y en el ejemplo que de estos pone Ulpiano: qua alia parte corporis quae contrara est ${ }^{27}$.

Teniendo en cuenta la sedes materiae donde se trata de los hermafroditas puede decirse que su nacimiento no suscitó mayores controversias, por tanto, al aspecto discordante con la habitualidad de la forma humana no tuvo relevancia suficiente como para cuestionar (y negar) la condición de personas. Puede decirse que su presencia se normalizó desde el punto de vista social y jurídico.

Cuestión distinta es cómo se entiende la anomalía física y las consecuencias que ésta tiene: el hermafrodita ¿es un enfermo?, ¿tiene un simple defecto físico no invalidante, sin mayor relevancia jurídica? Hay que recordar que, salvo que concurra otra patología, los hermafroditas no son inviables desde el punto de vista médico y, por tanto, su existencia no es incompatible con la vida.

La discordancia con la habitual forma humana es un claro ejemplo de defecto físico (por ejemplo, la polidactilia) pero ¿encajan los hermafroditas en la definición de enfermedad ofrecida por Sabino? Ulpiano nos recuerda cómo la define (D.21,1,1,7 Ulp. 1 ed. aed. curul.):

${ }^{26}$ Nos referimos al hermafroditismo puro, esto es, al nacimiento de personas que en grados variables muestran caracteres sexuales externos de ambos sexos. La carencia de datos fiables impide ofrecer una cifra exacta. Las Naciones Unidas estiman que entre el 0`5 y el 1'7\% de la población mundial es intersexual. En España no hay datos registrados de nacimientos de bebés intersex, pero parece que la frecuencia con la que se presenta es de 1/2000 casos.

27 Siguiendo con el razonamiento de Ulpiano y Paulo sobre las consecuencias que para los progenitores tienen estos partos, el hermafrodita no impediría a la madre beneficiarse del ius liberorum. Presupuesta la forma humana del hermafrodita tampoco computaría como parto fallido conforme al criterio de Paulo. 
Sed sciendum est morbum apud Sabinum sic definitum esse habitum cuiusque corporis contra naturam qui usum eius ad id facit deteriorem, cuius causa natura nobis eius corporis sanitatem dedit,

añadiendo que la enfermedad puede aparecer in toto corpore o alias in parte:

(namque totius corporis morbus est puta fvisis febris, partis veluti caecitas, licet homo itaque ${ }^{28}$ natus sit):

En el último inciso del fragmento, Ulpiano diferencia el vitium del morbus: aquel identificable con los defectos físicos, éste con la enfermedad propiamente dicha:

vitiumque a morbo multum differre, ut puta si quis balbus sit, nam hunc vitiosum magis esse quam morbosum,

aunque para Ulpiano (ego puto): aediles tollendae dubitationis gratia bis kata tou autou ${ }^{29}$ idem dixisse, ne qua dubitatio superesset.

Las consecuencias de las palabras de Ulpiano se recogen en el § 8 de D.21,1:

Proinde si quid tale fuerit viti sive morbi, quod usum ministeriumque hominis impediat, id dabit redhibitioni locum (...).

Los fragmentos transcritos están insertos en el título dedicado por los compiladores al examen de la rica casuística que suscitó la legitimación del comprador para el ejercicio de la actio redhibitoria y de la actio quanti minoris. Es cierto que el título del Digesto trata sobre todo de las enfermedades o defectos de los servi. Sin embargo, las soluciones que recoge son útiles para determinar el alcance de la anomalía anatómica de los hermafroditas, aunque no los cite expresamente.

Las consecuencias jurídicas de la anomalía anatómica son distintas para los hermafroditas esclavos y hermafroditas libres; esa diferencia justifica su examen por separado.

Comencemos con los servi. En estos, es obvio que saber a qué sexo pertenecen es una cuestión importante, pero más lo es determinar si el hermafroditismo es un defecto o una enfermedad. Si es este último caso, se plantea otro interrogante: ¿la enfermedad del hermafroditismo le inhabilita para el uso normal? Si es así, el vendedor, so pena de verse demandado, estaría obligado a informar al comprador del defecto, igual, por otra parte, que si se tratara de un simple defecto.

\footnotetext{
28 Ita dett.

${ }^{29}$ Id est: idem significantes.
} 
Para empezar, el hermafroditismo (naturalmente con el saber médico de la Antigua Roma), sería una enfermedad temporal, no permanente. No obstante, la duración no tiene mayor relevancia jurídica porque, como recuerda Ulpiano (1 ad ed. aedil curul.) adhiriéndose al parecer de Pomponio - D.21,1,6 pr., unas y otras dan lugar al ejercicio de las acciones previstas en el edicto edilicio:

Pomponius recte ait non tantum ad perpetuos morbos, verum ad temporarios quoque hoc edictum pertinere.

Aun siendo permanente la enfermedad o defecto, no parece que le impidiera realizar los servicios para los que fue comprado. La no legitimidad para el ejercicio de acciones se deduce sensu contrario de D. 21,1,1,8 (Ulp. 1 ad ed. aedil. curul.):

Proinde si quid tale fuerit vitii sive morbi, quod usum ministeriumque hominis impediat, id dabit redhibitioni locum, dummodo meminerimus non utique quodlibet quam levissimum efficere, ut morbosus vitiosusve habeatur (...).

Una consecuencia médica que las personas hermafroditas sufren es la impotencia. Según el parecer de Ulpiano (1 ad ed. aedil. curul.) - D.21,1,6,2 el impotente, igual que el hombre que padece criptorquidia, es un sujeto sano porque puede engendrar:

Spadonem morbosum non esse neque vitiosum verius mihi videtur, sed sanum esse, sicuti illum, qui unum testiculum habet, qui etiam generare potest.

Coincidimos con DALLA ${ }^{30}$ cuando afirma que la ausencia de enfermedad del impotente no deriva de la capacidad para engendrar, sino de la coincidencia con la apariencia masculina, La falta de legitimidad para el ejercicio de la acción redhibitoria se justifica por la plena aptitud del servus para el trabajo ya que tal defecto no disminuye el rendimiento que se espera de él.

Por el contrario, la impotencia si es una enfermedad, según el parecer de Paulo recogido por los compiladores a continuación del fragmento ulpianeo, cuando el sujeto carece de la parte del cuerpo necesaria para engendrar:

Sin autem quis ita spado est, ut tam necessaria pars corporis et ${ }^{31}$ penitus absit, morbosus est. (D. 21,1,7 Paul. 11 ad Sab.) (22. $^{32}$

30 DALLA, D., L'incapacità sessuale, cit., págs. 144-150.

${ }^{31}$ Et] ei dett.

32 Salvo el sin autem del comienzo (albertario, "Contributo alla critica de Digesto «, en Studi di diritto romano, Milán, 1953, pág. 114), el fragmento ha quedado a salvo de interpolaciones. 
Por razones obvias no nos detendremos en las dudas que ha provocado esta cuestión. Baste decir que la contradicción entre los textos citados no es tal si se interpretan como muestra del empeño por diferenciar los impotentes de los castrados $^{33}$. La impotencia generandi sí es una enfermedad, mientras que no lo es la impotencia coeundi. Las personas hermafroditas se ven afectadas de impotencia con independencia del fenotipo (masculino o femenino) que prevalezca en ellas.

Si la impotencia es una consecuencia del hermafrodismo también lo es la esterilidad. La manifestación natural y las implicaciones sociales asociadas a la maternidad se traducen en un tratamiento distinto de las consecuencias de la esterilidad en mujeres y hombres.

Trebacio distingue dos tipos de esterilidad -opinión que recuerda Celio en un fragmento del libro 1 ad ed. aed. curul, recogido por los compiladores en D.21,1,14,3- Para Trebacio la esterilidad es una enfermedad cuando su origen está en una anomalía corporal; en cambio la mujer cuya esterilidad no tiene causa anatómica que la justifique es una mujer sana:

De sterili Caelius distinguere Trebatium dicit, ut, si natura sterilis sit, sana sit, si vitio corporis, contra (D.21,1,14,3 Ulp. 1 ad ed. aedil. curul.).

Aplicada la distinción a las hermafroditas ${ }^{34}$, estas deben considerarse como enfermas porque, como decimos, la etiología de la esterilidad es la anomalía anatómica. Idéntica solución, por analogía con las causas de la esterilidad, tendría la amenorrea no natural:

Quae bis in mense purgatur, sana non est, item quae non purgatur, nisi per aetatem accidit (D. 21,1,15 Paul. 11 ad Sab.).

Más delicado es si el hermafrodismo puede derivar en enfermedad de espíritu. Paulo (11 ad Sab.-D.21,1,4,4 recuerda que los vicios o enfermedades del espíritu no permiten el ejercicio de la acción redhibitoria:

In summa si quidem animi tantum vitium est, redhiberi non potest, nisi si dictum est hoc abesse et non abest: ex empto tamen agi potest, si sciens id vitium animi reticuit: si autem corporis solius vitium est aut et corporis et animi mixtum vitium, redhibitio locum habebit.

Salvo que el vicio del espíritu sea una consecuencia de una enfermedad del cuerpo D.eod. 1:

33 Sobre la cuestión vid. DALla, D., L'incapacità, cit.

${ }^{34}$ Entiéndase personas en las que predominan los caracteres femeninos. 
Sed si vitium corporis usque ad animum penetrat, forte si propter febrem loquantur aliena vel qui per vicos more insanorum deridenda loquantur, in quos id animi vitium ex corporis vitio accidit, redhiberi posse.

$¿$ Se plantean las mismas dudas en el caso de que el hermafrodita sea una persona libre? Aquí habría que distinguir la trascendencia que el hermafroditismo tiene en el ámbito social de las consecuencias jurídicas que plantea. Desde el punto de vista social es indiferente que al sujeto libre hermafrodita se le considere enfermo o que tenga un defecto físico no invalidante (arg. ex. de D. 21,1,10,2 Ulp. 1 ad ed. aed. curul.). Jurídicamente tampoco tiene mayores consecuencias porque las personas libres no pueden ser objeto de negocio jurídicos. Lo realmente transcendente es determinar el sexo de los hermafroditas; este es el nudo gordiano del hermafroditismo.

\section{LA DETERMINACIÓN DEL SEXO DE LOS HERMAFRODITAS}

A la hora de encontrar un criterio para la determinación del sexo hay diferencias entre el tratamiento que el derecho romano y los derechos positivos hace de este problema. La primera, obvia, el alcance de la discusión: más limitada y planteada en términos distintos en derecho romano.

Por de pronto, la determinación del sexo en derecho romano no es perentoria para inscribir al neonato en un registro, pero sí resulta imprescindible para fijar, especialmente, la capacidad de obrar, por tanto, para conseguir que los negocios jurídicos en los que pudieran intervenir mujeres y hombres tuvieran efectos.

Ulpiano en los comentarios a Sabino plantea la duda sobre el criterio idóneo para discernir el sexo de las personas de apariencia ambigua:

Quaeritur: hermaphroditum cui comparamus? et magis puto eius sexus aestimandum, qui in eo praevalet. (D.1,5,10 Ulp. 1 ad Sab.)

Los compiladores insertaron el texto ulpianeo en el título dedicado al statu humanun. En este título, junto a fragmentos genéricos o descriptivos ${ }^{35}$, se recogen cuestiones relacionadas con la condición

${ }^{35}$ Cfr. D.1,5,1 Gai. 1 Inst.: Omne ius quo utimur vel ad personas pertinet vel ad res vel ad actiones. D.h.t. 3: Summa itaque de iure personarum divisio haec est, quod omnes homines aut liberi sunt aut servi. D.h.t. 4 Flor. 9 Inst.: (pr.) Libertas est naturalis facultas eius quod cuique facere libet, nisi si quid vi aut iure prohibetur. (1) Servitus est constitutio iuris gentium, qua quis dominio alieno contra naturam subicitur. (2) Servi ex eo appellati sunt, quod imperatores captivos vendere ac per hoc servare nec occidere solent. (3) Mancipia vero dicta, quod ab hostibus manu capiantur.

(C) UNED. Revista de Derecho UNED, núm. 24, 2019 
de libre o esclavo, la protección del nasciturus o la consideración como hijos legítimos. La obra de la que procede el fragmento aparece en la Palingenesia en una secuencia de textos donde Sabino examina supuestos dudosos de titularidad del ius testamentifactio ${ }^{36}$ : así, no lo tienen el pródigo (D. 28,1,18 pr.) o el condenado por libelo difamatorio (D. eod. 1), mientras que el reconocimiento del ius testamentifactio del hermafrodita depende de que su apariencia coincida con la de un varón.

El fragmento parece claro. Tan solo el «et magis puto» puede plantear alguna duda. A este respecto $\mathrm{WACKE}^{37}$ se pregunta si el propósito de Ulpiano fue excluir otras posibles soluciones. Estas, desde luego, no habrían pasado por reconocer un tercer sexo como categoría añadida a las de varón y hembra. Quiere esto decir que en la elección del criterio para determinar el sexo solo es posible optar entre $a$ ) el reconocimiento de la libertad individual del sujeto para, dentro del paradigma binario, identificarse con uno de los dos sexos (criterio subjetivo) y $b$ ) la enumeración de criterios objetivos.

La cuestión peliaguda es el sentido que debe darse a la expresión qui in eo praevalet. Una posible interpretación es atender, con los conocimientos médicos de la época, a la apariencia externa, de tal forma que los hermafroditas con caracteres más próximos a los de un hombre conseguirían sortear las restricciones para participar en la vida jurídica que tenían las mujeres.

El problema de esta interpretación surge en el hecho mismo de la comprobación. A quién corresponde hacerla o en qué momento deba hacerse son interrogantes que precisan una respuesta.

El criterio de la inspección individualizada no resulta extraño en derecho romano. La constatación de si un individuo ha alcanzado la pubertad es un ejemplo de la aplicación del mismo. Es conocida la controversia que sabinianos y proculeyanos mantuvieron al respecto; Gayo se hace eco en sus Instituciones 1,196 y se adhiere al parecer que proponen los primeros:

Masculi autem cum puberes esse coeperint, tutela liberantur: Puberem autem Sabinus quidem et Cassius ceterique nostri praeceptores eum esse putant, qui habitu corporis pubertatem ostendit, id est eum, qui generare potest; sed in his, qui pubescere non possunt, quales sunt spadones, eam aetatem esse spectandam, cuius aetatis puberes fiunt;

36 LENEl, O., Palingenesia Iuris Civilis. (1899, rist.1960).

37 WACKE, A., "Del hermafroditismo a la transexualidad», en Anuario de Derecho Civil, vol. 43, n. ${ }^{\circ}$ 3, 1990, pág. 691. 
sed diversae scholae auctores annis putant pubertatem aestimandam, id est eum puberem esse existimant, qui XIIII annos explevit.

Frente a la inspectio corporis caso por caso que propone los sabineanos, el fragmento menciona el criterio de la edad defendido por los proculeyanos.

En el mismo sentido se pronuncia Ulpiano 11,28, aunque añade la opinión de Prisco sobre la necesidad de que concurran la aptitud fisiológica y la edad:

Liberantur tutela masculi quidem pubertate. Puberem autem Cassiani quidem eum esse dicunt, qui habita corporis pubes apparet, id est qui generare possit: Proculeiani autem eum, qui quattuodecim annos expleuit: verum Priscus eum puberem esse, in quem utrumque concurrit et habitus corporis et numerus annorum (...).

Justiniano rechaza el criterio sabineano en I. 1,22 pr.:

Pupilli pupillaeque cum puberes esse coeperint, tutela liberantur. pubertatem autem veteres quidem non solum ex annis, sed etiam ex habitu corporis in masculis aestimari volebant. nostra autem maiestas dignum esse castitate temporum nostrorum bene putavit, quod in feminis et antiquis impudicum esse visum est, id est inspectionem habitudinis corporis, hoc etiam in masculos extendere: et ideo sancta constitutione promulgata pubertatem in masculis post quartum decimum annum completum illico initium accipere disposuimus, antiquitatis normam in femininis personis bene positam suo ordine relinquentes, ut post duodecimum annum completum viripotentes esse credantur (...).

y en C. 5,60,3:

Indecoram observationem in examinanda marum pubertate resecantes iubemus: quemadmodum feminae post impletos duodecim annos omnimodo pubescere iudicantur, ita et mares post excessum quattuordecim annorum puberes existimentur, indagnatione corporis inhonesta cessante.

La inspección ocular como criterio para determinar el sexo del neonato hermafrodita tendría sentido en el momento del nacimiento o, tras el alumbramiento, cuando los caracteres secundarios presentaran dudas.

El siguiente interrogante se refiere al lugar dónde debería quedar registrado el sexo. Augusto instituyó los registros como herramienta útil con la que comprobar los requisitos previstos en las leyes Aelia Sentia y Papia Poppea ${ }^{38}$. Trascurridos treinta días (en ocasiones, más como recuerda Macrobio en Saturnales 1,16,36) desde que se impusiera el nombre al recién nacido, procedía la ins-

${ }^{38} \mathrm{El}$ primer registro del que se tienen constancia data del año 62 d.C.

(C) UNED. Revista de Derecho UNED, núm. 24, 2019 
cripción. No consta en el «asiento registral» una referencia expresa al sexo del inscrito, por tanto, hay que suponer que la asignación del sexo se debía deducir del nombre. Por supuesto, tampoco se exigía - ni existía - un certificado o declaración hecha por especialistas con la que acreditar el sexo. Si a esto sumamos que, por un lado, el funcionario no tenía obligación de comprobar la veracidad y, por otro, hasta la reforma de Marco Aurelio que permitió la inscripción de los hijos ilegítimos, el alcance de la professio natalis se torna bastante limitado y en nada ayuda a esclarecer el sexo que se atribuye al hermafrodita.

Cuando realmente surgen los problemas de determinación del sexo es en la edad adulta, ya que después del alumbramiento, el criterio de la inspección ocular resulta inoperante pues sería necesario cada vez que el hermafrodita pretendiera participar en un negocio jurídico.

Partiendo de la no coincidencia del criterio jurídico con el criterio médico-biológico, podría pensarse en recurrir a la apariencia externa (lo que hoy se denomina sexo fenotípico) como criterio para determinar el sexo. Esto es lo mismo que decir «lo que más parezca prevalecer», por tanto, aquello que más semejanza presente con la normalidad varón/hembra.

Pero tampoco este criterio se libra de inconvenientes. Piénsese, por ejemplo, en la necesidad de conocer (establecer) qué porcentaje de caracteres (masculinos o femeninos) se precisan para atribuir uno u otro sexo. Las dificultades que plantea lo descartan como opción.

¿Qué otro criterio podría utilizarse? $\mathrm{WACKE}^{39}$ recurre a las palabras de Paulo (3 Sent.) recogidas D. 22,5,15,1:

Hermaphroditus an ad testamentum adhiberi possit, qualitas sexus incalescentis ostendit.

El autor interpreta el inciso qualitas sexus incalescentis ostendit como apetito sexual de forma que sería la libido la determinante del sexo. La dificultad que él mismo reconoce para probar el deseo sexual le lleva a descartarlo. En su lugar se pronuncia a favor del criterio del comportamiento social que exterioriza el hermafrodita.

Reconocer relevancia jurídica a la forma de comportarse en la vida social salva los inconvenientes de los caracteres externos. Ahora la cuestión es si la forma de comportarse en la vida social

39 WACKE, A., «Del hermafroditismo», cit., págs. 677-712. 
se corresponde con la autopercepción del sujeto. Esto es difícil de probar, pero lo que sí puede decirse es que el comportamiento social deja entrever la forma con la que se perciben las personas $^{40}$.

El derecho se pone al servicio de lo que socialmente se espera de hombres y mujeres, sin embargo, en los casos dudosos acerca del sexo las personas ambiguas gozan de cierta libertad para decidir a qué sexo pertenecen alejándose de lo prescrito en el ius.

En la solución que ofrecen los textos, sin que pueda decirse que se acogen a lo que hoy entendemos por identidad de género, sí hay cierta aproximación a ella desde el momento en que la autopercepción como criterio para determinar el sexo prima la libertad del sujeto sobre cualquier otro criterio.

\section{PARTICIPACIÓN DE LOS HERMAFRODITAS EN LA VIDA JURÍDICA}

Como hemos visto, el derecho romano establece más diferencias entre mujeres y hombres que las anatómico-biológicas. Las limitaciones en la capacidad jurídica y de obrar de aquellas exige la certeza del sexo de la persona que interviene en el negocio jurídico.

Dos fragmentos referidos a cuestiones de derecho sucesorio contemplan la intervención de los hermafroditas en alguno de los actos propios de aquel.

El primero, D. 28,2,6,2, de Ulpiano (3 Sent.) en el que se duda de la capacidad para instituir heredero.

Después de recordar en el inciso inicial del $\S p r$. la opinión favorable de Casio y Javoleno de que qui generare facile non possit nombre heredero a un póstumo, pues uxorem ducere et adoptare potest, en el mismo parágrafo se recuerda que también el impotente puede nombrar heredero. Casio y Labeón fundamentan su decisión de aplicar idéntico régimen en el hecho de que la edad y la esterilidad no son variables relevantes para que un sujeto pueda nombrar heredero:

${ }^{40}$ La idea de adoptar el sexo que prevalece en razón de los que el hermafrodita siente de sí mismo es defendida por costa, J.c. "Evolución sobre la consideración de la persona en Roma. El caso en particular del hermafroditismo», XVII Encuentro Nacional de Profesores de Derecho Romano de la República Argentina: Homenaje al profesor Luis Rodolfo Arguello, vol. 1, pág. 63.

(C) UNED. Revista de Derecho UNED, núm. 24, 2019 
Sed est quaesitum, an is, qui generare facile $e^{41}$ non possit, postumum heredem facere possit, et scribit cassius et iavolenus posse: nam et uxorem ducere et adoptare ${ }^{42}$ potest: spadonem quoque posse postumum heredem scribere et labeo et cassius scribunt: quoniam nec aetas nec sterilitas ei rei impedimento est.

A continuación, el $\S 1$ recoge el parecer de Juliano quien en esta cuestión sigue la opinión de Próculo - como recuerda el propio Ulpiano- de ahí el pronunciamiento contrario a un castrado pueda instituir heredero a un póstumo ${ }^{43}$; las palabras del inciso final del parágrafo qui iure utimur tienen el viso de operar como criterio general para resolver la cuestión. Este criterio termina por imponerse:

Sed si castratus sit, Iulianus Proculi opinionem secutus non putat postumum heredem posse instituere, quo iure utimur ${ }^{44}$.

Es en el $\S 2$ donde la posibilidad del hermafrodita de instituir heredero a un póstumo se condiciona a que prevalezca la apariencia del sexo masculino:

Hermaprhoditus plane, si in eo virila praevalebunt, postumun heredem instituere poterit.

Tratándose de una afirmación general nada dice de cómo, quien o en qué momento se constata qué sexo predomina. La respuesta de estos interrogantes reenvía la cuestión al análisis de los requisitos de la personalidad que hemos hecho en páginas anteriores.

La participación del hermafroditus en los negocios propios del derecho de sucesiones no se limita a cuestionar su legitimación para

41 [facile] bonfante, P., Corso di diritto romano 1, Diritto di familia, Milano, 1963 pág. 196 n.1.

${ }^{42}$ En duda de si [et adoptare] es una glosa.

43 Hay diferencia entre castrados, impotentes y estériles. Una posible explicación de que el castrado no pueda intervenir en determinados negocios jurídicos es que, al sufrir la mutilación de las gónadas, carecen de apariencia física masculina. En Roma se distinguen varios tipos de castrados. En todo caso es claro que los hermafroditas con "predominio" masculino gozan de mejor situación jurídico social que los eunucos o castrados. Sobre la cuestión, vid. CuATRECASAS, A., Amor y sexualidad en la Antigua Roma, ed. Difusión Jurídica y Temas de Actualidad, Madrid, 2009.

${ }^{44}$ En contra se pronuncia Gayo 1,103: Illud vero utriusque adoptionis commune est, quod et hi, qui generare non possunt, quales sunt spadones, adoptare possunt. Idéntica restricción se recoge en D.1,7,2,1 Gai. 1 Inst.: Illud utriusque adoptionis commune est, quod et hi qui generare non possunt, quales sunt spadones, adoptare possunt. El defecto físico del spadone no le impide tener heredero mediante arrogatio, D. 1,7,40,2 (Mod. 1 diff.): spado adrogando suum heredem sibi adsciscere potest nec ei corporale vitium impedimento est. El cambio de criterio sobre los eunucos es obra, según BONFANTE, P., Corso, cit., pág. 41, de los compiladores. A su juicio (pág. 41, n.2), la opinión de FERRINI, C., aunque se ha aceptada mayoritariamente, es errónea. 
la testamentifactio activa. Las dudas también se plantean sobre su posible intervención como testigo en un testamento. Este es el caso del que trata Paulo 3 Sent. en D.22,5,15,1:

Hermaphroditus an ad testamentum adhiberi possit, qualitas sexus incalescentis ostendit.

El fragmento de Paulo sigue al de Papiniano de adult. D.22,5,14. Y son los dos textos que en el título dedicado por los compiladores a quienes, cómo, cuándo y en qué condiciones se puede actuar como testigo, se examina la idoneidad de los hermafroditas como testigos de un testamento. Papiniano prohíbe la función testifical al condenado por adulterio:

Scio quidem tractatum esse, an ad testamentum faciendum adhiberi possit adulterii damnatus: et sane iuste testimonii officio ei interdicetur. existimo ergo neque iure civili testamentum valere, ad quod huiusmodi testis processit, neque iure praetorio, quod ius civile subsequitur, ut neque hereditas adiri neque bonorum possessio dari possit,

y Paulo se pronuncia sobre la falta de capacidad para intervenir en un testamento de quienes hayan sido condenados:

Repetundarum damnatus nec ad testamentum nec ad testimonium adhiberi potest. (D. 22,5,15 pr.).

Conforme a la regla de que solo a los hombres podían actuar como testigos en los negocios jurídicos es lógico que solo cuando prevaleciera en él el sexo masculino pueda intervenir. Pero la cuestión renvía a la interpretación de la expresión «el sexo que predomine».

En definitiva, es claro que en el criterio del predominio defendido por los juristas romanos, la libertad del individuo manifestada a través de su propia autopercepción es determinante para adscribirse a uno u otro sexo. Como hemos dicho, esa libertad individual encierra algo parecido a lo que hoy denominamos identidad de género.

\section{ALGUNAS CONCLUSIONES}

El examen de las fuentes romanas que directamente tratan del hermafroditismo dejan claro que este fenómeno no suscitó especiales preocupaciones entre los juristas. En todo caso, esas preocupaciones, salvo en tiempos pretéritos en los que ficción y realidad se cofunden, no surgen en el momento del parto.

Las clases de seres que cumplen con la exigencia de la forma humana como requisito de la personalidad solo indirectamente se re- 
fieren a las personas hermafroditas. Causas de esta omisión pueden ser, por un lado, el escaso número de nacimientos de hermafroditas puros que, con los conocimientos médicos de la época, podrán detectarse, y por otro, la ausencia (por lo menos hasta época clásica) de un registro en el que fuera obligatorio hacer constar el sexo del neonato.

En la edad adulta la necesidad de atribuir al hermafrodita un sexo, que solo puede ser el de hombre o mujer, excluye cualquier otra categoría. Los juristas romanos no admitieron, ni siquiera contemplaron, la posibilidad de admitir un tertius genus.

El criterio que propone Ulpiano para determinar el sexo tiene todos los visos de operar como criterio general. Puede decirse que las palabras de Ulpiano no tienen más alcance que el hacer desaparecer la posible discordancia entre el criterio jurídico y el criterio anatómico-biológico.

Que la ambigüedad de los caracteres sexuales secundarios (sexo fenotípico) solo plantee problemas cuando el hermafrodita pretenda intervenir en negocios de derecho sucesorio, hace pensar que para los juristas romanos lo importante era que el hermafrodita tuviera la apariencia externa normal del varón.

Es un anacronismo hablar de autopercepción de género en derecho romano, sin embargo, sí hay en el criterio de lo que más parezca prevalecer algo parecido a ello. La idea es que el comportamiento social es una manera de manifestar la percepción que un sujeto tiene de sí mismo. 